\title{
The Effects of Sports-Recreational Activities on the Inclusion of Young Montenegrins in Society
}

\author{
Bojan Masanovic ${ }^{1}$ \\ ${ }^{1}$ University of Montenegro, Faculty for Sport and Physical Education, Niksic, Montenegro
}

\begin{abstract}
The aim of this study was to determine whether there are differences in the level of social inclusion between respondents who are not at all engaged in sports activities and respondents who engage in sports and recreational activities once or twice a week. The sample included 60 subjects divided into two subsamples, 35 respondents who are not at all involved in sports activities and 25 respondents who practice sports and recreational activities once or twice a week. For research purposes, respondents voluntarily applied to the standardized Social Inclusion Scale questionnaire. To determine the significance of differences in the degree of social involvement between groups, was used t-test at the level of significance of $p<0.05$. It was concluded, based on these results, that between pairs of individual entities, a significant difference exists only in the fourteenth question (I have friends I see or talk to every week). There is no statistically significant difference for the other 17 pairs in the system of comparable parameters.
\end{abstract}

Key words: Social Inclusion, Sports Activity, Social Inclusion Scale

\section{Introduction}

To have the possibility and capacity for full and productive participation in economic, social and cultural life, as well as to enjoy the standard of living, that is, the welfare that is considered normal in a developed community, is to be socially involved (Commission of the European Communities, 2000). In contrast, social exclusion is a shortened term for what can happen when community members suffer from a combination of related problems such as unemployment, incompetence, low income, inadequate living conditions, poor health conditions, high crime rates and deteriorated relationships in the family (Social Exclusion Unit, 2001).

Davidson, Stayner, Nickou, Styron, and Chinman (2001) have established three dimensions of social inclusion that are related to friendship, the feeling of personal value and optimism, which leads us to the conclusion that a person can not be considered socially involved unless he is not capable to realize friendship experiences at a certain degree, to perform useful and meaningful activities in society and to hope for an even better future. However, about $11 \%$ of the adult population can be considered socially excluded (Jehoel-Gijsbers \& Vrooman, 2007), which can be a huge problem for the entire community. If such a significant part of the society is separated from the part of the population that normally lives and contributes to the community, the whole society will be harmed. Therefore, society increasingly applies interventions of any kind aimed at increasing social inclusion. The inclusion of as many people as possible in any form of activity and co-operation is shown to be a key in the recovery from mental problems, the reduction of poor mental health and the increase in mental strength (Wilson \& Seckter, 2015).

Social inclusion, understood as a multi-dimensional concept, includes physical, psychological, social and professional aspects (Le Boutillier \& Croucher, 2010). So, if physical activity, as we know, positively influences all these dimensions, and if we certainly know from previous research that it can positively influence mental health, and also help to recover both mentally and physically (Biddle \& Asare, 2011; Mašanović, Popovic, Bjelica, Vukotic, Zoric, 2018, Masanovic, Popovic, Vukotic, 2019; Popovic, Bjelica, Masanovic, \& Gardasevic, 2019), then we must use it.

\section{Montenegro}

Sport

\section{Correspondence:}

\section{B. Masanovic}

University of Montenegro, Faculty for Sport and Physical Education, Narodne omladine bb, 81400 Niksic, Montenegro

E-mail: bojanma@ucg.ac.me 
The aim of this research was to determine whether there are differences in the level of social inclusion between respondents who are not at all engaged in sports activities and respondents who engage in sports and recreational activities once or twice a week.

\section{Methods}

This study covered 60 respondents aged between 18 and 26, divided into two subsamples. The first subsample consists of 35 respondents who are not at all engaged in sports activities, while the other subsample consists of 25 respondents who engage in sports and recreational activities once or twice a week. The criterion for participating in the experiment was that the subjects were older than 18 years and that they had no health problems.

A research technique determining the level of social inclusion was a survey in which a standard questionnaire called Social Inclusion Scale was used, consisting of 18 questions divided into 3 chapters, or the scale which has three subscales that measure social isolation, social relations and social acceptance (Wilson \& Secker, 2015). The scale consists of statements in which respondents choose one of the options on the Likert's scale (1: "Not at all", 2: "Not particularly", 3: "Yes a little" and 4: "Yes definitely") that best describes their relationship with other people in the past month.

Filling out the questionnaire lasted an average of $10 \mathrm{minu}-$ tes, and respondents volunteered to participate in the research. Prior to the interview, all respondents were asked to sign an agreement confirming that they were willing to take part in it. It should be noted that the survey was anonymous and that all responses were strictly confidential. In spite of that, the respondents were able to revoke their participation in the survey at any time to which none of them decided.

Empirical data were analyzed through a statistical package for social sciences SPSS 20.0 (Chicago, IL, USA). The descriptive statistics were expressed as a means and standard deviation for each variable. To determine the significance of differences in the degree of social involvement between groups, a t-test for small independent samples was used. The significance was set at an alpha level of 0.05 .

\section{Results}

This section presents the results of central tendency and dispersion parameters, as well as the results of t-test for independent samples, classified into tables.

Looking at the average values of the results obtained with the Social Inclusion Scale (Table 1), on average, we see positive answers in 15 out of a total of 18 questions when it comes to a group of respondents who are not at all engaged in sports activities. In the group of respondents who deal with sports-recreational activities once or twice a week, the situation is very similar, and on average, we see positive answers in 16 of the total of 18 questions. Also, we can notice that a group of respondents who are not at all engaged in sports activities have on average more positive answers to 10 of the total of 18 questions. A group of respondents who deal with sports-recreational activities once or twice a week responded positively to 8 questions from a total of 18 on average.

Table 1. Descriptive statistical parameters for assessing the degree of social inclusion of both groups of respondents (inactive and active)

\begin{tabular}{llcc}
\hline Subscale & Question & $\begin{array}{c}\text { Inactive } \\
\text { Mean } \pm \text { SD }\end{array}$ & $\begin{array}{c}\text { Active } \\
\text { Mean } \pm \text { SD }\end{array}$ \\
\hline Isolation & I have felt terribly alone and isolated & $1.63 \pm .81$ & $1.68 \pm .80$ \\
& I have felt accepted by my friends & $3.63 \pm .55$ & $3.48 \pm .71$ \\
& I have been out socially with friends & $3.51 \pm .57$ & $3.48 \pm .65$ \\
& I have felt I am playing a useful part in society* & $2.86 \pm .88$ & $2.92 \pm .81$ \\
& I have friends I see or talk to every week* & $3.43 \pm .66$ & $3.52 \pm .82$ \\
\hline Relations & I have felt I am playing a useful part in society* & $3.11 \pm .80$ & $3.16 \pm .85$ \\
& I have felt what I do is valued by others & $3.26 \pm .78$ & $3.16 \pm .80$ \\
& I have been to new places & $2.97 \pm .82$ & $3.16 \pm .85$ \\
& I have learnt something about other cultures & $2.91 \pm .82$ & $3.04 \pm .89$ \\
& I have been involved in a group not just for my university studies & $2.63 \pm 1.00$ & $2.44 \pm 1.08$ \\
& I have done some cultural activity & $2.11 \pm .93$ & $2.2 \pm 1.00$ \\
& I have felt some people look down on me because of how I am & $1.69 \pm .96$ & $2.04 \pm .98$ \\
& I have felt unsafe to walk alone in my neighbourhood in daylight & $1.57 \pm 1.01$ & $1.52 \pm .82$ \\
\hline Acceptance & I have friends I see or talk to every week* & $3.66 \pm .54$ & $3.24 \pm .83$ \\
& I have felt accepted by my neighbours & $3.60 \pm .65$ & $3.44 \pm .71$ \\
& I have felt accepted by my family & $3.69 \pm .63$ & $3.56 \pm .77$ \\
& I have felt clear about my rights & $3.34 \pm .77$ & $3.32 \pm .69$ \\
& I have felt free to express my beliefs & $3.29 \pm .79$ & $3.28 \pm .79$ \\
\hline
\end{tabular}

Note: Mean - Arithmetic mean; SD - Standard deviation; * - Items in more than one subscale

Based on the results shown in Table 2, it can be clearly seen that between the pairs of individual entities, a significant difference exists only in the fourteenth question (I have friends I see or talk to every week). For all other couples in the system of comparable parameters there is no significant difference, i.e. in the other 17 questions, there is no significant difference between respondents who are not at all engaged in sports activities and respondents who engage in sports and recreational activities once or twice a week. 
Table 2. Differences in the degree of social inclusion between inactive and active respondents

\begin{tabular}{|c|c|c|c|c|c|c|}
\hline Subscale & Questions & Activity & Mean & SD & $\mathbf{F}$ & Sig \\
\hline \multirow[t]{10}{*}{ Isolation } & \multirow[t]{2}{*}{ I have felt terribly alone and isolated } & Inactive & 1.63 & .808 & -.244 & .808 \\
\hline & & Active & 1.68 & .802 & & \\
\hline & \multirow[t]{2}{*}{ I have felt accepted by my friends } & Inactive & 3.63 & .547 & .913 & .365 \\
\hline & & Active & 3.48 & .714 & & \\
\hline & \multirow[t]{2}{*}{ I have been out socially with friends } & Inactive & 3.51 & .658 & .199 & .843 \\
\hline & & Active & 3.48 & .653 & & \\
\hline & \multirow[t]{2}{*}{ I have felt I am playing a useful part in society* } & Inactive & 2.86 & .879 & -.282 & .779 \\
\hline & & Active & 2.92 & .812 & & \\
\hline & \multirow[t]{2}{*}{ I have friends I see or talk to every week* } & Inactive & 3.43 & .655 & -.479 & .634 \\
\hline & & Active & 3.52 & .823 & & \\
\hline \multirow[t]{16}{*}{ Relations } & \multirow[t]{2}{*}{ I have felt I am playing a useful part in society* } & Inactive & 3.11 & .796 & -.213 & .832 \\
\hline & & Active & 3.16 & .850 & & \\
\hline & \multirow[t]{2}{*}{ I have felt what I do is valued by others } & Inactive & 3.26 & .780 & .471 & .640 \\
\hline & & Active & 3.16 & .800 & & \\
\hline & \multirow[t]{2}{*}{ I have been to new places } & Inactive & 2.97 & .822 & -.864 & .391 \\
\hline & & Active & 3.16 & .850 & & \\
\hline & \multirow[t]{2}{*}{ I have learnt something about other cultures } & Inactive & 2.91 & .818 & -.566 & .573 \\
\hline & & Active & 3.04 & .889 & & \\
\hline & \multirow{2}{*}{$\begin{array}{l}\text { I have been involved in a group not just for my } \\
\text { university studies }\end{array}$} & Inactive & 2.63 & 1.003 & 695 & .490 \\
\hline & & Active & 2.44 & 1.083 & & \\
\hline & \multirow[t]{2}{*}{ I have done some cultural activity } & Inactive & 2.11 & .932 & -.341 & .735 \\
\hline & & Active & 2.20 & 1.000 & & \\
\hline & \multirow{2}{*}{$\begin{array}{l}\text { I have felt some people look down on me be- } \\
\text { cause of how I am }\end{array}$} & Inactive & 1.69 & .963 & -1.396 & .168 \\
\hline & & Active & 2.04 & .978 & & \\
\hline & \multirow{2}{*}{$\begin{array}{l}\text { I have felt unsafe to walk alone in my neighbour- } \\
\text { hood in daylight }\end{array}$} & Inactive & 1.57 & 1.008 & .210 & .835 \\
\hline & & Active & 1.52 & .823 & & \\
\hline \multirow[t]{10}{*}{ Acceptance } & I have friends I see or talk to every week* & Inactive & 3.66 & .539 & 2.359 & .022 \\
\hline & Active & 3.24 & .831 & & & \\
\hline & \multirow[t]{2}{*}{ I have felt accepted by my neighbours } & Inactive & 3.60 & .651 & .903 & .370 \\
\hline & & Active & 3.44 & .712 & & \\
\hline & \multirow[t]{2}{*}{ I have felt accepted by my family } & Inactive & 3.69 & .631 & 695 & .490 \\
\hline & & Active & 3.56 & .768 & & \\
\hline & \multirow[t]{2}{*}{ I have felt clear about my rights } & Inactive & 3.34 & .765 & .119 & .906 \\
\hline & & Active & 3.32 & .690 & & \\
\hline & \multirow[t]{2}{*}{ I have felt free to express my beliefs } & Inactive & 3.29 & .789 & .028 & .978 \\
\hline & & Active & 3.28 & .792 & & \\
\hline
\end{tabular}

Note: Mean - Arithmetic mean; SD - Standard deviation; F - value of Levene's test of equality of variances; Sig - significance of two-tailed testing of arithmetic mean difference; ${ }^{*}$ - Items in more than one subscale

\section{Discussion}

The results of this study show that physical activity is not in a positive correlation with the degree of social inclusion of young Montenegrins, which is in contrast to the majority of previous studies that clearly indicate that there is a positive impact of activities such as sports and recreation on social inclusion (Bailey, 2005; Skinner, Zakus, \& Cowell, 2008; Kelly, 2011; Bjelica, Popovic, Masanovic, \& Gardasevic, 2019). Nevertheless, the mentioned studies do not provide accurate data on the statistical significance of the sport's impact, which in a way suggests that we must accept their results with a dose of reserve. However, in litereatures we can find the opposite results, which are somewhat in correlation with the results of this study. In other words, we can find research that negates the statistically significant influence of sports on the social inclusion of young people, and nevertheless do not deny that some aspects of social inclusion are more positive after participating in organized sports and recreational activities (Masanovic, 2019). The inconsistencies we encounter in all previous studies lead us to conclude that this area needs to be further examined. In the end, it is interesting to mention the third group of research that indicates that any organized activity that influences the suppression of loneliness positively affects the social inclusion of the individual (Perkins, 2010), regardless of whether it is sport or any other social engagement. Most of the experts in the field of Sport Sciences will give priority to the sport, as its advantage is that besides raising social inclusion, the participants also get a positive impact on the health and quality of life, which would again mean that they solved two problems with one move (personal communication, S Popovic). 
It is important to admit some of the limitations of this research. In the first place, the sample of respondents is not large enough to generalize the conclusion, so the next study should be conducted on a larger sample of respondents. The next fact is that the extent of an active group's exercise may not be sufficient to make any difference, so the next study should examine a population that daily practiced sports and recreational activities. Finally, when it comes to young people, the chance that they are socially excluded is much lower than when it comes to older people, because the feature of this age is optimism and a desire for progress and proving, and their daily schedule is filled with different activities (education, job and career, family creation and conditions for existence) that suppress the sense of social exclusion. A person who is active has lower opportunities to think about some negative aspects of life and, can not be socially excluded because, an individual can not be considered socially excluded if he does not feel socially excluded (Onken, Craig, Ridgway, Ralph, \& Cook, 2007; Pinfold, 2000). This approach could certainly contribute to the quality of the results obtained, and in this way would enable more representative data on the basis of which it would gain an accurate insight into the social inclusion of young people, but would not reduce the contribution of this preliminary study.

Acknowledgements

There are no acknowledgements.

\section{Conflict of Interest}

The authors declare that there are no conflicts of interest.

Received: 24 April 2019 | Accepted: 19 May 2019 | Published: 4 July 2019

\section{References}

Bailey, R. (2005). Evaluating the relationship between physical education, sport and social inclusion. Educational Review, 57(1), 71-90, doi: 10.1080/0013191042000274196

Biddle, S.J.H., \& Asare, M. (2011). Physical activity and mental health in children and adolescents: a review of reviews. British Journal of Sports Medicine, 45(11), 886-895. doi: 10.1136/bjsports-2011-090185

Bjelica, D., Popovic, S., Masanovic, B., \& Gardasevic, J. (2019). Impact of professional sports engagement on the extension of life: a systematic review. In BMC Sports Science, Medicine and Rehabilitation Supplement of 5th International Scientific Conference on Exercise and Quality of Life, 11(P9, Suppl 1), 18, Novi Sad: Faculty of Sport and Physical Education, University of Novi; doi: 10.1186/s13102-019-0119-7.
Commission of the European Communities. (2000). Social Policy Agenda: Communication from the Commission to the Council, the European Parliament, the Economic and Social Committee and the Committee of the Regions. Brussels: Commission of the European Communities.

Davidson, L., Stayner, D., Nickou, T., Styron, M., \& Chinman, M. (2001). Simply to be let in: Inclusion as a basis for recovery. Psychiatric Rehabilitation Journal, 24(4),375-388. doi: 10.1037/h0095067

Jehoel-Gijsbers, G., \& Vrooman, C. (2007). Explaining Social Exclusion. Hague: The Netherlands Institute for Social Research/SCP.

Kelly, L. (2011). Social inclusion through sports-based interventions? Critical Social Policy, 31(1), 126-150. doi: 10.1177/0261018310385442

Le Boutillier, C., \& Croucher, A. (2010). Social inclusion and mental health British Journal of Occupational Therapy, 73(3),136-139.

Masanovic, B. (2019). Impact of Physical Exercise Programs and Programs of Social Activity on Public Health and Social Inclusion of Young People. Iranian Journal of Public Health, 48(6).

Masanovic, B., Popovic, S., \& Vukotic, M. (2019). Working ability factors as a protective mechanism against social exclusion of older people: A systematic review. In Book of Abstracts of the 16th Annual Scientific Conference of Montenegrin Sports Academy "Sport, Physical Activity and Health: Contemporary Perspectives" (95), Cavtat: Montenegrin Sports Academy.

Mašanović, B., Popović, S., Bjelica, D., Vukotic, M., \& Zoric, G. (2018). The effects of physical activity on depressive symptoms among elderly people: a systematic review. In Proceedings World Congress of Performance Analysis of Sport XII (423). Opatija: International Society of Performance Analysis of Sport.

Onken, S., Craig, C., Ridgway, P., Ralph, R., \& Cook, J. (2007). An analysis of the definitions and elements of recovery: Areview of the literature. Psychiatric Rehabilitation Journal, 31(1), 9-22. doi: 10.2975/31.1.2007.9.22

Perkins, D. (2010). Activation and social inclusion: challenges and possibilities. Australian Journal of Social Issues, 45(2), 267-287. doi: 10.1002/ j.1839-4655.2010.tb00178.x

Pinfold, V. (2000). "Building up safe havens...all around the world": Users' experiences of living in the community with mental health problems. Health and Place, 6(3), 201-212. doi: 10.1016/S1353-8292(00)00023-X

Popovic, S., Bjelica, D., Masanovic, B., \& Gardasevic, J. (2019). Exercise for cognitive health as a proxy for the social inclusion of older people: a systematic review. In BMC Sports Science, Medicine and Rehabilitation Supplement of 5th International Scientific Conference on Exercise and Quality of Life, 11(P8, Suppl 1), 17-18, Novi Sad: Faculty of Sport and Physical Education, University of Novi; doi: 10.1186/s13102-0190119-7.

Skinner, J., Zakus, D. H., \& Cowell, J. (2008). Development through Sport: Building Social Capital in Disadvantaged Communities. Sport Management Review, 11(3), 253-275. doi: 10.1016/s1441-3523(08)70112-

Social Exclusion Unit. (2001). Preventing social exclusion. London: Office of the Deputy Prime Minister.

Wilson, C., \& Secker, J. (2015). Validation of the Social Inclusion Scale with Students. Social Inclusion, 3(4),52-62. doi: http://dx.doi.org/10.17645/ si.v3i4.121 